\title{
ER, PR, cerb-B2, ki-67, p53, Bcl-2, CYCLIN-D1 EXPRESSIONS IN INVASIVE BREAST CARCINOMAS AND COMPARISON WITH THE CLINICAL AND HISTOPATHOLOGICAL PARAMETERS
}

\author{
Özgür İlhan Çelik ${ }^{1 *}$, Serkan Yaşar Çelik², Yelda Dere', Özcan Dere ${ }^{4}$, Önder Özcan ${ }^{5}$ \\ *1,2,3 Muğla Sitkı Koçman University, Faculty of Medicine, Department of Pathology \\ ${ }^{4,5}$ Muğla Sitkı Koçman University, Faculty of Medicine, Department of Surgery
}

*Corresponding Author: -

\begin{abstract}
: -
Aim:The aim of this study was to evaluate ER(Estrogen-receptor), PR(Progesteronreceptor), cerb-B2, ki-67, p53, Bcl2(B cell lymphoma-2), Cyclin-D1 expressions in invasive breast carcinomas and compare them with the clinical and histopathological parameters.

Methods: We analyzed 70 female patients retrospectively who underwent Modified Radical Mastectomy with Axillary lymph node dissection and were diagnosed as Invasive ductal carcinoma of the breast-Not otherwise specified at Muğla Sitkı Koçman University, Faculty of Medicine, Department of Pathology between 2012 and 2016.

$E R, P R$, cerb-B2, ki-67, p53, Bcl-2, Cyclin-D1 expressions of these tumors were obtained by immunohistochemistry. Clinical parameters of the patients were obtained from the hospital automation system.

Results: Bcl-2; was found to be more positive in patients with young age, small and lowgrade, ER/ PR-positive tumors without distant organ metastasis. However, Bcl-2 negativity was found to be higher in p53, cerb-B2 positive and fastlygrowing (tumors with high ki67 index) tumors.

Cyclin-D1; was found to be more positive in small and low-grade, slowly-growing (tumors with low ki-67 index), cerbB2 and p53 negative tumors without vascular invasion and axillary lymph node metastasis.

Conclusion: These results were interpreted as; Bcl-2 and Cyclin-D1 positivity were in favor of better outcome and better prognosis.
\end{abstract}

Keywords: Breast carcinoma, ER, PR, cerb-B2, ki-67, p53, Bcl-2, Cyclin-D1

\section{(c) $(3)$ (1)}




\section{INTRODUCTION}

Breast cancer is the most common type of cancer among women. It accounts for $23 \%$ of all female cancers. The main treatment of breast cancer is surgery. However, adjuvant chemotherapy, hormone therapy and/or radiotherapy can be added if needed. Various immunohistochemical tests are being used for determining the hormone receptors and gene expressions which are important in patient-based treatment and predicting prognosis $(1,2)$.

Estrogen receptor (ER) and progesteron receptor (PR) are nuclear transcription factors that induce growth of normal breast epithelial cells. Also, they affect the growth of breast cancers which express ER and PR. PR expression is regulated by ER. That's why the PR expression shows the stability and functionality of ER pathway. In invasive breast cancers, ER and PR expressions can be determined by immunohistochemistry on formalin fixed, parafine embedded tissues (1-3).

cerb-B2 is a transmembrane glycoprotein located in the chromosome 17 which codes a growth factor on the surface of normal breast epithelial cells. It is reported that $15 \%$ of breast cancers show amplification of cerb-B2 associated with higher protein expression $(1,4)$.

Ki-67(MIB-1) expression which is seen in all proliferating cells, is being investigated as a prognostic factor of breast cancer in various studies. The prognostic value of ki-67 has been recognized, especially in early breast cancers (5-7). p53 is a gene located in the chromosome 17 preventing proliferation of mutated cells. Wild type p53 is a tumor suppressor protein which has a role in the genomic stability by apoptosis when DNA repair mechanisms cannot save the cell. When p53 is mutated, it begins to accumulate in the nucleus by posttranscriptional modification. p53 mutation is seen in 18 $25 \%$ of primary breast cancers $(7,8)$.

The expressions of ER and PR are associated with good prognosis and long-term survival whilst cerb-B2 and p53 gene expressions and high ki-67 proliferation index points out poor prognosis (1-3,5-8).

Bcl-2(B cell lymphoma-2) is one of the most important anti-apoptotic genes and can be immunohistochemically determined. In the recent years, controversial results have been declared in different studies in some of which Bcl-2 expression was associated with good prognosis and vice versa $(9-12,13,14)$

Cyclin-D1 is a protein regulating G1 to S phase transition of cell cycle. High expression of Cyclin-D1 is reported in welldifferentiated and slowly growing breast cancers in some of the studies however it is found to have no prognostic effect in others $(15,16)$.

In this study, we aimed to determine the expressions of the well-known prognostic markers such as ER, PR, cerb-B2, p53 and ki-67 in additon to novel proteins of Bcl-2 and Cyclin-D1 in breast cancer.

\section{METHODS:}

Patients: We analyzed 70 female patients retrospectively who underwent Modified Radical Mastectomy with Axillary lymph node dissection without any neoadjuvant theraphy and were diagnosed as Invasive ductal carcinoma of the breastNot otherwise specified in Department of Pathology of our hospital in this study.

This Project was evaluated by Research and Publication Ethics Committee of our hospital and it was approved in terms of scientific researches and patient ethics.

Immunohistochemistry: The hematoxylin-eosin slides of these patients were reviewed and representative sections and paraffin blocks of each tumor appropriate for immunohistochemistry were selected. ER, PR, cerb-B2, p53, ki-67, Bcl-2 and Cyclin-D1 antibodies were applied to the four micrometer thick sections of formaldehyde fixed paraffin embedded tumor blocks by Leica Bond-Max brand fully automatic immunohistochemistry device. For each slide, hematoxylin was used as the counterstain. The antibodies used were as follows: anti-ER: Bond ready to use-7ml; PA0151-Leica, anti-PR: Bond ready to use-7ml; PA0312-Leica, anti-cerb-B2: NCL-L-CB11 (ready to use7ml; Novocastra), anti-p53: ready to use-7ml; PA0057-Leica, anti-ki-67: ready to use-7ml;

PA0230-Leica, anti-Bcl-2: ready to use-7ml; PA0117-Leica, anti-Cyclin-D1: NCL-LCYCLIN D1-GM (ready to use-7ml; Novocastra). Immunstaining was evaluated with the light microscope (Olympus, BX46 Clinical Microscope- Japan).

\section{Clinical and the pathological parameters of the patients and the evaluation methods:}

Clinical parameters of the patients were obtained from the hospital automation system. The parameters evaluated were age, tumor localization, tumor size, tumor grade according to the Modified Bloom Richardson grading system (1,17), the presence of Ductal carcinoma in situ (DCIS) $(1,18,19)$, vascular invasion $(1,20)$, axillary lymph node $(1,21)$ and distant organ metastasis at the time of diagnosis $(1,22)$.

Nuclear staining for ER and PR were accepted as positive. The 'expression rate', the extent of staining for both antibodies, were scored according to the number of nuclear stained carcinoma cells in 100 tumor cells. As determined by International Committees, the presence of $1 \%$ or more nuclear positive tumor cells was considered as positive $(123,24)$.

The evaluation of cerb-B2 was also done according to the criters of International Committees. The cases more than $10 \%$ of the tumor cells which were strongly all around membranous stained were accepted as cerb-B2 positive $(1-4,25,26)$.

Ki-67 positivity was evaluated as follows: The nuclear staining of the tumor cells was counted in three 40xmagnification area and averaged in the peripheral region of the tumor where the tumor cells were more rapidly proliferating and had more potential of invasiveness. Cases with lower than 15\% ki-67 index were accepted as 'Low ki-67 index'.

Cases with $15 \%$ or more ki-67 index were accepted as 'High ki-67 index' (5).

If nuclear staining was detected even in one of the invasive tumor cells, the case was considered p53 positive (7). The presence of cytoplasmic staining in more than $10 \%$ of invasive tumor cells were considered positive for Bcl-2 evaluation $(9,11)$. The presence of nuclear staining in more than $30 \%$ of invasive tumor cells were considered positive for CyclinD1 evaluation (15). 


\section{Statistical evaluation:}

The Kolmogorov-Smirnov test and Q-Q Plot were used to verify the normality of the distribution of continuous variables. Descriptive statistics and categorical variables were given as frequencies (percentages). Statistical analysis of clinical data between two groups consisted of Mann-Whitney U-test for non-parametric data, whereas the Chisquare/Fisher's exact tests were used for categorical variables. Analyses were performed with SPSS Statistics for Windows, Version 20 and two-tailed p-value less than and equal to 0.05 was considered statistically significant.

\section{RESULTS:}

The parameters evaluated and the relations were given in the Table 1 and Table 2. The mean age of 70 female patients included in the study was 57.4 (min 35-max 90). Most of the patients were over 40 years of age whilst four of them were under 40. The relation of age with the ki-67 index, p53, Bcl-2 and Cyclin-D1 expressions were not statistically significant. Left breast localization was more common than right breast localization. Only Cyclin-D1 expression was higher in left breast-located tumors. The microscopic size of the tumors varied between 0.5 and $6 \mathrm{~cm}$. The only statistically significant result was in p53 expression. p53 positivity was higher in tumors larger than $2 \mathrm{~cm}$ diameter.

When tumors were graded according to the Modified Bloom-Richardson grading system $(1,17)$; statistically significant results were obtained in ki-67 and p53 expressions. ki-67 proliferation index was lower in grade 1 tumors; however, it was higher in grade 3 tumors. Also, p53 positivity was lower in grade 1 tumors and higher in grade 3 tumors. Presence of DCIS accompanying to the tumors were seen more in p53 positive tumors. Tumors with vascular invasion had high ki67 index and more p53 expressions; however these tumors showed lower Cyclin-D1 expressions.

Tumors with axillary lymph node metastasis also had high ki-67 index and more p53 expressions; however, these tumors showed lower Cyclin-D1 expressions as in the vascular invasion. There wasn't any statistically significant result in distant metastasis. ER positive tumors had lower ki-67 index. This significance wasn't seen in p53, Bcl-2 and Cyclin-D1 expressions. PR positive tumors tend to show lower ki-67 index and higher Bcl2 expressions. However, this was not statistically significant.

cerb-B2 tumors had high ki-67 index and tend to show higher p53 but lower Cyclin-D1 expressions. There wasn't any statistically significant result in ki-67 index in correlation with Bcl-2 and Cyclin-D1 expressions. However, tumors with lower ki-67 index tend to show more Bcl-2 expressions.

Also, there wasn't any statistically significant result in p53 expression in correlation with Bcl-2 and Cyclin-D1 expressions. However, p53 negative tumors tend to show more Bcl-2 expressions.

The relation between Bcl-2 and Cyclin-D1 were statistically significant. Bcl-2 positive tumors were also Cyclin-D1 positive. The result was the same in the case of negativity.

\section{DISCUSSION}

Breast cancer which is mainly treated with surgery has many prognostic factors such as tumor size, axillary or distant metastasis, vascular invasion, hormone receptor status which effects other treatment options, chemotherapy, hormone therapy, and/or radiotherapy $(1,27)$. In addition to the expressions of the well-known immunohistochemical markers (ER, PR, cerb-B2, p53 and ki-67), two novel antibodies, Bcl-2 and Cyclin-D1, were discussed in our study.

The age distribution of the patients was similar with the literature and age had no significant relation with ki-67, p53, Bcl2 and Cyclin-D1 expressions. But younger patients had lower ki-67 proliferation rate similar with the study of Soliman et al (5). Older patients showed higher p53 positivity. Although this relation was not significant, it was concordant with when compared with the study of Yang et al (8). Bcl-2 positivity was more common in younger patients similar with the study of Seong et al (9).

In our study, most of the tumors were located in the left breast $(64.3 \%)$ and localization showed no significant relation with ki-67, p53 and Bcl-2. But right breast localization showed a significant relation with Cyclin-D1 negativity. However even it was not statistically significant, tumors located in left breast showed higher ki-67 rate and p53 positivity and thought to have aggressive behaviour.

Tumors smaller than $2 \mathrm{~cm}$ had lower ki-67 rate whilst larger than $2 \mathrm{~cm}$ had higher ki-67 rate similar with the literature even the relation was not statistically significant (5-7). p53 positivity was more common in tumors larger than 2 $\mathrm{cm}(\mathrm{p}=0.02)(7)$. Bcl-2 and Cyclin-D1, as reported by Seong and Mylona et al, was more commonly positive in small tumors $(9,15)$.

Ki-67 proliferation rate was significantly higher in high grade tumors $(\mathrm{p}=0.005)$ as expected and reported by Colditz ( 1 ), Soliman (5), Abubakar (6) and Pan (7) at al. as well as p53 positivity (8) ( $\mathrm{p}=0.022)$. Bcl-2 and Cyclin-D1 were commonly negative similar with the studies of Seong and Mylona $(9,15)$.

Tumors with DCIS which are generally associated with aggressive behaviour and high recurrence rates, p53 positivity was significantly higher but ki-67, Bcl-2 and CyclinD1 had no statistical relation (1).

The most well-known prognostic factors such as vacular invasion, axillary and distant metastasis were reported to have higher ki-67 rate by various studies $(1,5-8,13,14)$. We also found that vascular invasive tumors had higher ki-67 rate and p53 positivity in addition to Cyclin-D1 negativity in accordance with the literature. Also, axillary node positive tumors showed higher ki-67 index, more p53 expression and Cyclin-D1 negativity as reported $(1,5-7,8)$ but Bcl-2 expression showed no similarity with the literature (9). In cases with distant metastasis ki-67 rate and p53 positivity was higher whereas Bcl-2 was generally negative as Yu and Yang et al. reported $(13,14)$. 


\section{CONCLUSION}

We assessed two novel proteins, Bcl-2 and Cyclin-D1 for breast cancer in addition to the classical biomarkers (ER, PR, cerb B2, ki-67, p53). Bcl-2 positivity was more common in younger patients, smaller and lower grade, ER and PR positive tumors with no metastasis. But the Bcl-2 positivity seen in rapidly growing, p53 and cerb-B2 positive tumors made us think Bcl-2 may not be very reliable in predicting prognosis.

Cyclin-D1 positivity was significantly higher in small, low-grade, slowly growing (low Ki-67 rate), vascular non-invasive and non-metastatic tumors in addition to cerb-B2, p53 negative tumors.

All these results supported the studies reporting Bcl-2 and Cyclin-D1 in favor of better prognosis. However, we could not completely exclude that they may indicate aggressive behaviour as declared in some studies (9). We think that these controversial results may be due to tumor heterogeneity and should be supported by larger studies with higher number of cases.

Table 1: The parameters evaluated.

\begin{tabular}{|c|c|c|c|c|}
\hline Parameter & & & & \\
\hline Age $($ mean=57.4) & $<\mathbf{4 0}$ & & $=40 />40$ & Total \\
\hline$(\mathrm{n}-\%)$ & $4-5.7$ & & $66-94.3$ & $70-100$ \\
\hline Tumor localization & Left breast & & Right breast & \\
\hline$(\mathrm{n}-\%)$ & $45-64.3$ & & $25-35.7$ & $70-100$ \\
\hline $\begin{array}{l}\text { Tumor diameter } \\
\text { (mean:2.3cm) }\end{array}$ & $\leq 2 \mathrm{~cm}$ & & $>2 \mathrm{~cm}$ & \\
\hline$(n-\%)$ & $38-54.3$ & & $32-45.7$ & $70-100$ \\
\hline Tumor grade & 1 & 2 & 3 & \\
\hline$(\mathrm{n}-\%)$ & $6-8.6$ & $49-70.0$ & $15-21.4$ & $70-100$ \\
\hline $\begin{array}{l}\text { Ductal carcinoma } \\
\text { in situ }\end{array}$ & Present & & Absent & \\
\hline$(\mathrm{n}-\%)$ & $36-51.4$ & & $34-48.6$ & $70-100$ \\
\hline Vascular invasion & Present & & Absent & \\
\hline$(\mathrm{n}-\%)$ & $37-52.9$ & & $33-47.1$ & $70-100$ \\
\hline $\begin{array}{l}\text { Axillary lymph } \\
\text { node metastasis }\end{array}$ & Present & & Absent & \\
\hline$(\mathrm{n}-\%)$ & $32-45.7$ & & $38-54.3$ & $70-100$ \\
\hline $\begin{array}{l}\text { Distant organ } \\
\text { metastasis }\end{array}$ & Present & & Absent & \\
\hline$(\mathrm{n}-\%)$ & $6-8.6$ & & $64-91.4$ & $70-100$ \\
\hline ER & Positive & & Negative & \\
\hline$(\mathrm{n}-\%)$ & $58-82.9$ & & $12-17.1$ & $70-100$ \\
\hline PR & Positive & & Negative & \\
\hline$(\mathrm{n}-\%)$ & $52-74.3$ & & $18-25.7$ & $70-100$ \\
\hline Cerb-B2 & Positive & & Negative & \\
\hline$(\mathrm{n}-\%)$ & $27-38.6$ & & $43-61.4$ & $70-100$ \\
\hline Ki-67 index & Low & & High & \\
\hline$(\mathrm{n}-\%)$ & $32-45.7$ & & $38-54.3$ & $70-100$ \\
\hline $\mathrm{p53}$ & Positive & & Negative & \\
\hline$(\mathrm{n}-\%)$ & $40-57.1$ & & $30-42.9$ & $70-100$ \\
\hline
\end{tabular}


Table 2: The statistical evaluation of the parameters with the immunstaining (Statistically significant $p$ values are written in bold)

\begin{tabular}{|c|c|c|c|c|c|c|c|c|c|}
\hline & & \multicolumn{2}{|l|}{ Ki-67 } & \multicolumn{2}{|l|}{ p53 } & \multicolumn{2}{|l|}{ Bcl-2 } & \multicolumn{2}{|c|}{ Cyclin-D1 } \\
\hline & & Low & High & - & + & $=$ & + & - & + \\
\hline \multirow{3}{*}{$\begin{array}{l}\text { Age } \\
(\mathrm{n}-\%)\end{array}$} & P value & \multicolumn{2}{|c|}{$(\mathrm{p}=0,226)$} & \multicolumn{2}{|l|}{$(\mathrm{p}=0,181)$} & \multicolumn{2}{|c|}{$(\mathrm{p}=0,150)$} & \multicolumn{2}{|c|}{$(\mathrm{p}=0,720)$} \\
\hline & $<40$ & $3-75$ & $1-25$ & $3-75$ & $1-25$ & $0-0$ & 4-100 & $2-50$ & $2-50$ \\
\hline & 40 or $>40$ & $29-43,9$ & $37-56,1$ & $27-40,9$ & $39-59,1$ & $23-34,8$ & $43-65,2$ & $39-59,1$ & $27-40,9$ \\
\hline \multirow{3}{*}{$\begin{array}{l}\text { Tumor } \\
\text { localization } \\
(\mathbf{n}-\%)\end{array}$} & P value & \multicolumn{2}{|c|}{$(\mathrm{p}=0,074)$} & \multicolumn{2}{|l|}{$(\mathrm{p}=0,098)$} & \multicolumn{2}{|c|}{$(p=0,676)$} & \multicolumn{2}{|c|}{$(p=0,027)$} \\
\hline & $\begin{array}{l}\text { Left } \\
\text { breast }\end{array}$ & $17-37,8$ & $28-62,2$ & $16-35,6$ & $29-64,4$ & $14-31,1$ & $31-68,9$ & $22-48,9$ & $23-51,1$ \\
\hline & $\begin{array}{l}\text { Right } \\
\text { breast }\end{array}$ & $15-60$ & $10-40$ & $14-56$ & $11-44$ & $9-36$ & $16-64$ & $19-76$ & $6-24$ \\
\hline & P value & \multicolumn{2}{|c|}{$(\mathrm{p}=0,206)$} & \multicolumn{2}{|l|}{$(p=0,022)$} & \multicolumn{2}{|c|}{$(p=0,448)$} & \multicolumn{2}{|c|}{$(p=0,540)$} \\
\hline \multirow{2}{*}{$\mid \begin{array}{l}\text { Tumor size } \\
(\mathbf{n}-\%)\end{array}$} & $\leq 2 \mathrm{~cm}$ & $20-52,6$ & $18-47,4$ & $21-55,3$ & $17-44,7$ & $11-28,9$ & $27-71,1$ & $21-55,3$ & $17-44,7$ \\
\hline & $>2 \mathrm{~cm}$ & $12-37,5$ & $20-62,5$ & $9-28,1$ & $23-71,9$ & $12-37,5$ & $20-62,5$ & $20-62,5$ & $12-37,5$ \\
\hline \multirow{4}{*}{$\begin{array}{l}\text { Tumor } \\
\text { grade } \\
(\mathrm{n}-\%)\end{array}$} & P value & \multicolumn{2}{|c|}{$(p=0,005)$} & \multicolumn{2}{|c|}{$(p=0,022)$} & \multicolumn{2}{|c|}{$(\mathrm{p}=0,195)$} & \multicolumn{2}{|c|}{$(p=0,904)$} \\
\hline & 1 & $5-83,3$ & $1-16,7$ & $4-66,7$ & $2-33,3$ & $0-0$ & 6-100 & $3-50$ & $3-50$ \\
\hline & 2 & $24-49$ & $25-51$ & $25-51$ & $24-49$ & $18-36,7$ & $31-62,5$ & $29-59,2$ & $20-40,8$ \\
\hline & 3 & $3-20$ & $12-80$ & $1-6,7$ & $14-93,3$ & $5-33,3$ & $10-66,7$ & $9-60$ & 6-40 \\
\hline \multirow{3}{*}{\begin{tabular}{|l} 
Ductal \\
carcinoma \\
in situ \\
$(\mathrm{n}-\%)$ \\
\end{tabular}} & P value & \multicolumn{2}{|c|}{$(p=0,794)$} & $(p=0,009)$ & & $(\mathrm{p}=0,352$ & & $(p=0,967$ & \\
\hline & Absent & $15-44,1$ & $19-55,9$ & $20-58,8$ & $14-41,2$ & $13-38,2$ & $21-61,8$ & $20-58,8$ & $14-41,2$ \\
\hline & Present & $17-47,2$ & $19-52,8$ & $10-27,8$ & $26-72,2$ & $10-27,8$ & $26-72,2$ & $21-58,3$ & $15-41,7$ \\
\hline Vascular & P value & $(p=\mathbf{0 , 0 0}$ & & $(p=0,009)$ & & $(\mathrm{p}=0,936$ & & $(p=0,035$ & \\
\hline invasion & Absent & $21-63,6$ & $12-36,4$ & $29-87,9$ & $4-12,1$ & $11-33,3$ & $22-66,7$ & $15-45,5$ & $18-54,5$ \\
\hline$(\mathrm{n}-\%)$ & Present & $11-29,7$ & $26-70,3$ & $1-2,7$ & $36-97,3$ & $12-32,4$ & $25-67,6$ & $26-70,3$ & $11-29,7$ \\
\hline Axillary & P value & $(p=0,00$ & & $(p=0,000)$ & & $(\mathrm{p}=0,439$ & & $(p=0,035$ & \\
\hline lymph node & Absent & $24-63,2$ & $14-36,8$ & $28-73,7$ & $10-26,3$ & $14-36,8$ & $24-63,2$ & $15-45,5$ & $18-54,5$ \\
\hline $\begin{array}{l}\text { metastasis } \\
(\mathrm{n}-\%)\end{array}$ & Present & $8-25$ & $24-75$ & $2-6,3$ & $30-93,7$ & $9-28,1$ & $23-71,9$ & $26-70,3$ & $11-29,7$ \\
\hline Distant & P value & $(p=0,13$ & & $(\mathrm{p}=0,175)$ & & $(p=0,439$ & & $(p=0,065$ & \\
\hline organ & Absent & $31-48,4$ & $33-51,6$ & $29-45,3$ & $35-54,7$ & $19-29,7$ & $45-70,3$ & $6-50$ & $6-50$ \\
\hline $\begin{array}{l}\text { metastasis } \\
(\mathrm{n}-\%)\end{array}$ & Present & $1-16,7$ & $5-83,3$ & $1-16,7$ & $5-83,3$ & $4-66,7$ & $2-33,3$ & $3-50$ & $3-50$ \\
\hline ER & P value & $(\mathbf{p}=\mathbf{0 , 0 2}$ & & $(\mathrm{p}=0,927)$ & & $(p=0,165$ & & $(p=0,985$ & \\
\hline & Absent & $2-16,7$ & $10-83,3$ & $5-41,7$ & $7-58,3$ & $6-50$ & $6-50$ & $7-58,3$ & $5-41,7$ \\
\hline & Present & $30-51,7$ & $28-48,3$ & $25-43,1$ & $33-56,9$ & $17-29,3$ & $41-70,7$ & $34-58,6$ & $24-41,4$ \\
\hline PR (n-\%) & P value & $(\mathrm{p}=0,07$ & & $(p=0,693)$ & & $(p=0,225$ & & $(\mathrm{p}=0,800$ & \\
\hline & Absent & $5-27,8$ & $13-72,2$ & $7-38,9$ & $11-61,1$ & $8-44,4$ & $10-55,6$ & $11-61,1$ & $7-38,9$ \\
\hline & Present & $27-51,9$ & $25-48,1$ & $23-44,2$ & $29-55,8$ & $15-28,8$ & $37-71,2$ & $30-57,7$ & $22-42,3$ \\
\hline Cerb-B2 (n- & P value & $(\mathbf{p}=\mathbf{0 , 0 0}$ & & $(\mathrm{p}=0,436)$ & & $(\mathrm{p}=0,555$ & & $(\mathrm{p}=0,800$ & \\
\hline$\%)$ & Absent & $26-60,5$ & $17-39,5$ & $20-46,5$ & $23-53,5$ & $13-30,2$ & $30-69,8$ & $22-51,2$ & $21-48,8$ \\
\hline & Present & 6-22,2 & $21-77,8$ & $10-37$ & $17-63$ & $10-37$ & $17-63$ & $19-70,4$ & $8-29,6$ \\
\hline
\end{tabular}

\section{REFERENCES:}

[1].Colditz G, Chia KS. Invasive breast carcinoma. In: WHO Classification of tumours of the breast. 4th ed. Lyon, IARCH;2012. p. 14-38.

[2].Elesawy BH, El-hafez AA, Shawky AE, Arafa M. Immunohistochemistry-based subtyping of breast carcinoma in Egyptian women: A clinicopathologic study on 123 patients. Ann Diagn Pathol 2014;18:21-6.

[3].Lee A, Park WC, Yim HW, Lee MA, Park G, Lee KY. Expression of cerb-B2, Cyclin-D1 and Estrogen Receptor and their clinical implications in the Invasive Ductal Carcinoma of the breast. Jpn J Clin Oncol 2007;37(9):708-14.

[4].Allred DC. Issues and updates: evaluating estrogen receptor-alpha, progesteron receptor and HER2 in breast cancer. Mod Pathol 2010;23(2):52-9.

[5].Soliman NA, Yussif SM. Ki-67 as a prognostic marker according to breast cancer molecular subtype . Cancer Biol Med 2016;13(4):496-504.

[6].Abubakar M, Orr N, Daley F, et al. Prognostic value of automated Ki-67 scorring in breast cancer: a centralised evaluation of 8088 patients from 10 study groups. Breast Cancer Res 2016;18:104. DOI: 10.1186/s13058-016-07656.

[7].Pan Y, Yuan Y, Liu G, Wei Y. P53 and Ki-67 as prognostic markers in triplenegative breast cancer patients. PLoS ONE 2017;12(2):e0172324. 
[8].Yang P, Du CW, Kwan M, Liang SX, Zhang GJ. The impact of p53 in predicting clinical outcome of breast cancer patients with visceral metastasis. Scientific Reports 2013;3:2246. DOI: 10.1038/srep02246.

[9].Seong MK, Lee JY, Byeon J, et al. Bcl-2 is a highly significant prognostic marker of hormone-receptor-positive, human epidermal growth factor receptor-2-negative breast cancer. Breast Cancer Res Treat 2015;150:141-8.

[10]. Dawson SJ, Makretsov N, Blows FM, et al. Bcl-2 in breast cancer: a favourable prognostic marker across molecular subtypes and independent of adjuvant therapy. Br J Cancer 2010;103:668-75.

[11]. Callagy GM, Pharoah PD, Pinder SE, et al. Bcl-2 is a prognostic marker in breast cancer independently of the Nottingham prognostic index. Clin Cancer Res 2006;12:2468- 75.

[12]. Eramah E, Buhmeida A, Khaled BR, et al. Prognostic value of Bcl-2 expression among women with breast cancer in Libya. Tumor Biol 2013;34:1569-78.

[13]. Yu B, Sun X, Shen HY, Gao F, Fan YM, Sun ZJ. Expression of the apoptosis-related genes Bcl-2 and BAD in human breast carcinoma and their associated relationship with chemosensitivity. J Exp Clin Cancer Res 2010;29:17.

[14]. Yang Q, Moran MS, Haffty BG. Bcl-2 expression predicts local relapse for early stage breast cancer receiving conserving surgery and radiotherapy. Breast Cancer Res Treat 2009;115:343-8.

[15]. Mylona E, Tzelepis K, Theohari I, Giannopoulou I, Papadimitriou C, Nakopoulou L. Cyclin-D1 in invasive breast carcinoma: favourable prognostic significance in unselected patients and within subgroups with an aggressive phenotype. Histopathol 2013;62:472-80.

[16]. Peurala E, Koivunen P, Haapasaari KM, Bloigu R, Jukkola-Vuorinen A. The prognostic significance and value of Cyclin-D1, CDK4 and p16 in human breast cancer. Breast Cancer Res 2013, 15/1:R5:1-10.

[17]. Elston CW, Ellis IO. Pathological prognostic factors in breast cancer.The value of histological grade in breast cancer; experience from a large stugy with long term followup. Histopathol 1998;19:403-10.

[18]. Hughes LL, Wang M, Page DL, et al. Local excision alone without irradiation for ductal carcinoma in situ of the breast: a trial of the Eastern Cooperative Oncology Group. J Clin Oncol 2009;27:5319-24.

[19]. Solin LJ, Baehner FL, Butler S, Badve S, Yoshizawa C, Shak S. A quantitative multigene RT-PCR assay for predicting recurrence risk after surgical excision alone without irradiation for ductal carcinoma in situ (DCIS): a prospective validation study of the DCIS Score from ECOG E5194. Cancer Res 2011;71:108S.

[20]. Goldhirsch A, Ingle JN, Gelber RD, Coates AS, Thurlimann B, Senn HJ. Tresholds for therapies: highlights of the St Gallen International Expert Consensus on the primary theraphy of early breast cancer. Ann Oncol 2009;20:131929.

[21]. Cabioglu N, Ozman V, Kaya H, et al. Increased lymph node positivity in multifocal and multicentric breast cancer. J Am Coll Surg 2009;208:67-74.

[22]. Wu SG, Li H, Tang LY, et al. The effect of distant metastases sites on survival in de novo stage-IV breast cancer: A SEER database analysis. Tumour Biol 2017 Jun;39(6):1010428317705082.

[23]. Hammond ME, Hayes DF, Dowsett M, et al. American Society of Clinical Oncology/College Of American Pathologists guideline recommendations for immunohistochemical testing of estrogen and progesterone receptors in breast cancer. J Clin Oncol 2010 Jun 1;28(16):2784-95.

[24]. Hammond ME, Hayes DF, Dowsett M, et al. American Society of Clinical Oncology/College of American Pathologists guideline recommendations for immunohistochemical testing of estrogen and progesterone receptors in breast cancer. Arch Pathol Lab Med. 2010 Jun;134(6):907-22.

[25]. Epstein M, Ma Y, Press MF. Erb-B2 testing: assessment of status for targetted therapies. In: Diseases of the breast, 4th ed. Philadelphia: Wolters Kluwer Lippincott Williams\&Wilkins; 2010. P. 431-42.

[26]. Wolff AC, Hammond ME, Hicks DG, et al. American Society of Clinical Oncology; College of American Pathologists. Recommendations for human epidermal growth factor receptor 2 testing in breast cancer: American Society of Clinical Oncology/College of American Pathologists clinical practice guideline update. J Clin Oncol. 2013 Nov 1;31(31):3997-4013.

[27]. Juan Rosai. Breast.Rosai and Ackerman’s Surgical Pathology. Elsevier,10th ed 2011 